\title{
Research on Current Situation, Problems and Reform Measures in Chinese University Physical Education
}

\author{
Li Shengfu \\ Department of Physical Education, Wuhan Institute of Technology, Wuhan, Hubei, China, 430205 \\ shengfu@163.com
}

Keywords: current situation; problems and countermeasures; university physical education

\begin{abstract}
However, the present situation of university physical education in our country is not optimistic. Many aspects of physical education have problems such as teaching mode, teaching content, teaching object and teaching facilities. This paper puts forward the corresponding countermeasures in order to provide reference for relevant researchers.
\end{abstract}

\section{Current Situation of University Physical Education}

Under the strong support of the central government and the ministry of education, universities have set up the physical education management agency and PE teachers training institutions. They organized a number of full-time researchers various conditions for the development of standards, improving the teaching of physical education system. But often a lot of students in the graduation, and sports farewell, 10 years of physical education and sports teaching do not make the concept of lifelong sports, nor have the ability to develop physical training skills and good habits. Research shows that the physical quality of college students is generally decreased.The rate of modern disease in young people is significantly higher than ten years ago, a variety of diseases tend to be younger.Up to now, our country has carried out the students' physical health test for the 6 time. The results show that modern diseases are related to the lack of physical exercise.

The physical health of middle school students and college students in our country are not coordinated, the concrete manifestation is: high body, low quality, the improvement of the shape development level, the physical ability and the poor quality and so on. In addition, our country students' myopia rate increased year by year, especially the students in junior high school students myopia rate increased significantly; the quality of the outbreak and endurance and other quality levels were continued to decline. The reasons that cause the students' physical quality are in many aspects. First of all, in the middle and primary school sports teaching in our country, the sports teaching content is stale and monotonous, the form is monotonous and dull. Traditional sports imposed on sports skills and ability to teach and modern innovative teaching philosophy is not penetrate sports teaching practice course content cannot meet the physical and mental development of students and the demand, not to mention the creative, students after graduation are not used for example, shot-put, discus, javelin, high jump, long jump and other projects from primary school to repeat to the university. Before the roll and roll over is more than ten years, actually very few students in extracurricular or after graduation to them as a means of lifelong exercise. At present, our country elementary and junior high school university high school stage of the seemingly all-round development of sports teaching to help students develop movement in the growth process of habit, which leads to the students lack of physical fitness, physical fitness decreased from primary school to university sports teaching has neglected the physical teaching at all levels the internal relation and cohesion. Practice shows that the elementary school sports teaching material arrangement should focus on the cultivation of the students' learning interest and physical ability, all-round development of students on the basis of sports ability; middle school should focus on the cultivation of students' noncompetitive special skills; university stage, should pay attention to the concept of lifelong physical culture. The simple repetition of the course level becomes the "bottleneck" of the development of physical education". This concept of "lifelong physical education" has become the new task of the reform of physical education in universities. 


\section{Problems of University Physical Education}

\section{Backward Mode of University Physical Education}

Due to the influence of traditional physical education and examination oriented education, the teaching mode of physical education in universities in China is always the teacher-centered mode. This kind of teaching mode although in certain historical for sports education also play a certain role, but to limit the independence of the students, and ignore the cultivation of the students' physical ability, there exist some disadvantages. Over the years, the university sports teaching have been the extension of the traditional structure mode to complete the work of physical education. For example, in the preparation of the part of the sports, teachers always adopt the warm-up activities. This kind of fixed pattern is invariable, although achieves certain exercise effect, but can bring the dull negative effect to the student, causes it gradually loses the interest in the physical education. This kind of teaching process is too much emphasis on the structure of classroom teaching mode is the teacher subject theory mode of implementation of this model with the teacher as the leading, to simply teach skills, ignoring the students' physical and mental development. Although the teaching process seems to be unified and standardized, but the lack of students' personality and expertise is difficult to help students experience physical and mental pleasure.

\section{Outdated Content of University Physical Education}

At present, China's universities' physical education teaching materials mostly focus on physical competitive skills. Teaching content is year-round outdated, and does not reflect the nowadays social development of sports teaching training the real needs of the content, inconsistent with the times, poor usability. In addition, the teaching of physical education in most arrangements the individual teaching and training in sports, from the training objectives of modern sports teaching, to some extent ignored the most of the students participate in demand finally, compiling the textbook does not take into account the cultivation of students' personality and special skills and interests, is not conducive to the students on the basis of textbook knowledge form a set to suit their own training methods and exercise habits these problems directly lead to steps in the physical education teaching in universities. It focuses only on instilling the basic knowledge and skills, ignoring the needs of students' development.

\section{Short-sighted Objective of University Physical Education}

From primary school to university, physical education pays too much attention to the students' practical ability in sports, blindly pursuing short-term goals and benefits of the sports teaching.One-sided education will enhance physical education target attributed, even as the only or the final objective of physical education teaching, so that the students' lifelong sports consciousness cannot be good training. Sports teaching in universities, first of all is to set the teaching goal in our country universities sports teaching goal setting in the implementation to personal goals and social goals of organic coupling to the student's physical, psychological and social development together, failed to students' interest, hobbies combined with the concept of sport and exercise, can better realize students' personal value and social value. Realization of the value orientation of Chinese higher physical education from social value to the individual value, diversification to the cultivation of self-exercise ability effective policy is in the sports teaching in Colleges and universities, colleges and universities should be in line with the health first guiding ideology to set the teaching goal.The goal of universities physical educationshould also be ledto health personalized and lifelong training.

\section{Deficient Facilities of University Physical Education}

Many universities in our country always have the problems of the deficiency of facilities of sports teaching and extracurricular activities. The number of students in many universities has now increased by one or two times, but there is no increase in sports venues. This has caused some students even have to participate in extracurricular sports activities of the mind, it is difficult to achieve some university although more adequate sports facilities, but because of the class hour arrangement and project conflict and management problems, the actual serious shortage of places for physical education and extra-curricular activities. For example, some colleges and universities stadium tube facilities of the lack of, but limited to sports law and sports facilities in schools is 
community property, also yielded the opening to the outside world and contracting fees. This means that a lot of universities sports facilities are also facing the society, which directly causes the problems of deficient facilities in universities.

\section{Reform Measures of University Physical Education}

\section{Reform University Physical Education Mode}

The reform of teaching in universities should be gradually formed to adapt to different units, and different types of reasonable teaching mode. This set of teaching mode will guide the teaching of physical education in Colleges and universities to diversified development, including physical and mental health and lifelong sports consciousness training; combined with the traditional content and the emerging content, increase the new sports, pay attention to dance aerobics and other recreational activities; combination of main materials and auxiliary materials, emphasizing student's personal interest, with interest as the center to guide self-perfection. The classroom teaching and the extracurricular activities combined. General teaching method and the multimedia teaching means combined enhanced sports knowledge of interest; evaluation on students' motivation and effect of the Trinity, the sports learning process become a process of interaction between the subject and object of the teachers and students, so that students through learning assessment evaluation, in addition, also can through the sports community sports clubs will form of competition with teaching mode stimulate students' sense of competition, the cultivation of students' interest in sports and lifelong sports consciousness. Constantly updated knowledge and open up a new subject, explore new areas in the teaching practice, teachers should pay attention to the student's main body status, change of sports teaching in the past too much emphasis on teaching, actively adopt heuristic teaching method. In the pre class preparation, some sports games are usually added. This part has a fun and competitive features, which can create a pleasant learning atmosphere.

\section{EnhanceUniversity Physical Education Content}

For a long time, due to the curriculum management system and the development of competitive sports in our country, most of the sports curriculum in universities is the main content of competitive skills. Sports curriculum the content section appeared in connection with each other does not close, low level repetition, old phenomenon, is not conducive to the goal of cultivating the students' interest in sports teaching is too limited to enhance the physical fitness of students, ignoring the cultivation of physical exercise habits and lifelong sports idea, does not meet the physical and psychological characteristics of the students, deviated from the purpose of modern sports teaching. Reform and innovation of the content system of physical education is a breakthrough in the reform of physical education in China. Teaching content of physical education in the elementary school stage should be based; junior middle school stage is primary school to high school development transition period, should be the basic and special, especially considering the foundation; high school stage should be is the foundation and expertise, and focus should be settled in the specialty in universities and colleges, students should master the basic methods and skills of two or more exercise, actively improve the level of sports, sports development to, thus laying solid foundation of lifelong physical education. According to the cognitive rules of the adolescent and physical and mental development of the law, each student should master one or two physical education skills in the sports teaching stage to lay the foundation for lifelong physical education.

\section{Optimize University Physical Education Objective}

Universities physical education is the highest level of school physical education. Therefore, physical education should be to cultivate students' lifelong sports awareness and ability to specifically only to realize the teaching goal of elementary school, junior high school and high school levels, the highest level of higher education, and the teaching objectives may realize smoothly. University stage is the key period for the development of students' body shape and physical form. It is also the stage for students to go to the society and realize the social value. This is a key point for students to realize the transformation from individual value to social value. Therefore, college teachers should teach and urge the students to master the method of lifelong exercise, training their consciousness of lifelong physical education and make it a habit of lifelong 
exercise habit, so as to improve the students' physical health and mental health level. The most important in the teaching of physical education in universities is to help students master the sports skills and sports which meet their needs, so as to cultivate students' passion for physical training and the habit of lifelong sports. In addition to the practice ability of students' physical education in universities, we should help the students to have a good command of the new knowledge and the new skills.

\section{Improve University Physical Education Facilities}

Deepening the reform of physical education, we need plenty of sports venues and facilities.High levels physical education facilities support a high level of physical education, school physical education facilities needs in the premise of the school sports teaching open universities should provide adequate sports facilities venue for the student movement training group activities; on the other hand, the open university campus and more superior hardware conditions, making many people take the University as an important place for sports and fitness. However, it seems that the sports venues and resources are rich in the university. In fact, there is a contradiction between the supply and demand of sports venues. Universities sports facilities opening to the outside world should not consider profit for the sole purpose. Given the capacity of students, it can be set for free in a certain time period for students.

\section{Conclusion}

The reform of physical education in universities is the only way to achieve the goal of physical education in universities, and to complete the teaching task. To cultivate universitiesstudents' lifelong exercise habit, we must reform the physical education mode, the physical education contents, thephysical education objectives and thephysical education facilities to improve the physical education in Chinese universities.

\section{References}

[1] Liu Desong, Problems and Developing Countermeasures in the Chinese College P. E., J. Journal of Sports Adult Education, 2013(6):59-60.

[2] Ge Qing, Zhang Qiuya, Wen Jie, Establishment of Chinese College P.E. Syllabuses and Countermeasures, J., Journal of Wuhan Institute of Physical Education, 2012(3):87-90.

[3]Ma Jinfeng, P.E. Teaching Innovation in Chinese Colleges and Universities, J., Journal of Shandong Institute of Physical Education and Sports, 2014(4):105-109. 